\title{
Microcápsulas Vacías Empleadas en Aplicaciones de Ultrasonidos: Generalidades, Usos y Métodos de Fabricación
}

\author{
Jay Molino, PhD \\ Universidad Especializada de las Américas, Panamá
}

Doi: 10.19044/esj.2019.v15n12p394 URL:http://dx.doi.org/10.19044/esj.2019.v15n12p394

\section{Resumen}

Debido a su baja densidad, dispersión óptica, buen aislamiento térmico y grandes contenedores, las microcápsulas vacías han adquirido una especial relevancia en el campo farmacéutico y tecnológico como en la industria de cosméticos, recubrimientos, tintas, catálisis, estándares de columna de cromatografía, rellenos, biorreactores, fotocopiado electrónico, terapia génica, administración focalizada de fármacos o incluso en diagnóstico por imágenes de ultrasonido. Una microcápsula vacía se define como micro burbujas (CO2, N2, perfluorocarbonos "PFC") encapsuladas en una capa delgada de polímero o proteína. Si se emplean en aplicaciones de imágenes de ultrasonido, una capa lo suficientemente delgada permite que el núcleo de gas de la microcápsula oscile en presencia de un campo acústico para que la frecuencia de diagnóstico se pueda reflejar adecuadamente. Además, estas cápsulas deben ser no tóxicas, biocompatibles y biodegradables en el cuerpo humano. Esta revisión se centra en la síntesis de microcápsulas poliméricas biodegradables vacías que pueden emplearse como agentes de contraste de ultrasonido o en cualquier otra aplicación biomédica, donde los tamaños pequeños, la uniformidad y la toxicidad son parámetros cuando se fabrican dichas cápsulas.

Palabras clave: Microencapsulación, biodegradable, agentes de contraste de ultrasonidos, dosificación de fármacos, microcápsulas vacías, métodos de encapsulación 


\title{
Hollow Microcapsules in Ultrasound Applications: Generalties, Uses and Fabrication Methods
}

\author{
Jay Molino, PhD \\ Universidad Especializada de las Américas, Panamá
}

\begin{abstract}
Due to their low density, optical scattering, good heat insulation and large useful containers, hollow microcapsules have gained particular relevance in the pharmaceutical and technology realm such as in cosmetics, coatings, inks, catalysis, chromatography column standards, fillers, bioreactors, electronic photocopying, gene therapy, localized drug delivery or even in diagnostic ultrasound imaging. A hollow microcapsule is defined as microbubbles (CO2, N2, perfluorocarbons "PFC's") encapsulated in a thin polymer or protein shell. If they are employed in ultrasound imaging applications, a thin enough shell requirement allows the microcapsule gas core to oscillate in the presence of an acoustic field so that the characteristic frequency can be appropriately reflected; further, these capsules must be nontoxic, biocompatible, and biodegradable in the human body. This review focuses on the synthesis of hollow biodegradable polymeric microcapsules which can be employed as ultrasound contrast agent or any other biomedical applications as well, where small sizes, uniformity, and toxicity are parameters when fabricating such capsules.
\end{abstract}

Keywords: Microencapsulation, biodegradable, ultrasound contrast agents, drug delivery, hollow microcapsules, encapsulation techniques

\section{Introduction}

La encapsulación de materiales consiste en contener núcleos sólidos, líquidos o gaseosos dentro una cubierta/matriz o laminado hecha de polímero. El producto final es llamado microcápsula y sus tamaños están dados en escala micrométrica. Si el tamaño es nanométrico se llaman nanocápsulas o nanopartículas y la cubierta o el núcleo es orgánico o inorgánico (Benita, 2006), (Ghosh, 2006), (Narayan \& Wheatley, 1999), (Lin, Eckersley, \& Hall, 2009). La cubierta en mención es continua y puede ser o no se porosa. Una microcápsula no debe ser confundida con una microesfera ya que la última posee una sola estructura, es decir, son completamente sólidas y no posees espacios de almacenaje internos como una microcápsula. 
La micro encapsulación tiene numerosas aplicaciones en la industria de manufactura y en el campo de la biomédica puesto que representa un mecanismo efectivo para estabilizar el material que está siendo encapsulado, reduce el efecto tóxico y prolonga el tiempo de liberación de químicos funcionales en varios campos industriales. El proceso de micro encapsulación es un método efectivo para proteger componentes activos (aislarlos) de condiciones ambientales, evita la de-naturalización de componentes (e.g. proteger encimas de los esfuerzos cortantes en reactores tradicionales, proteólisis de microorganismos y reacciones hidrofóbicas) (Caussette, et al., 1999), (Colombié, Gaunand, \& Lindet, 2001), (Bommarius \& Karau, 2005), provee estabilidad para fármacos (e.g. protección contra fluidos biológicos) (Barrat, 2002), (Allen \& Cullis, 2004), aumenta la bio-compatibilidad de fármacos convencionales y permite la dosificación controlada de moléculas activas (Wise, et al., 2000), (Yang, Qiao, Hong, \& Dong, 2013), (Siepman \& A, 2001), elimina incompatibilidades, sirve de material inerte para el confinamiento de elementos incompatibles (Sang, Yang, Cui, Zhu, \& Sheng, 2005), es usada para fabricar micro reactores (Ikeuchi, Tane, \& Ikuta, 2012), (Murphy \& Wudl, 2010), andamios para cultivar tejidos, (Sukhorukov, Fery, \& Mohwald, 2005), y se usa para construir rellenos livianos/flotación, separadores o amortiguadores (Shchukin \& Sukhorukov, 2004). Las microcápsulas también pueden ser empleadas como células artificiales, (Ouyang, et al., 2004) como cubiertas protectoras para encimas y tejidos (Cao, 2005) (Colvin, 2003), o como vectores de transferencia para terapia genética (Selvam, et al., 2006; Baker, 2010), dispersantes de colorantes (Luo Yan, 2002), sistemas de purificación de agua (Sohn, et al., 2012), electrodos (Lee, Jung, \& Oh, 2003), almacenadores de gas (Tamae, Sumi, \& Yasuda, 1996), catalizadores, (Ikeda, et al., 2006) cosméticos (Cheng, et al., 2009). Finalmente representan métodos asequibles para revestimientos funcionales orgánicos e inorgánicos.

En sí, el proceso de micro encapsulación es una manera efectiva de combinar las propiedades de diferentes materiales, algo muy difícil de lograr si se emplean otros métodos. Muchas otras aplicaciones han sido discutidas en el trabajo de Dubey et al (Lachman, Lieberman, \& Kanig, 2010) y Lachman et al (Dubey, Shami, \& KU, 2009), pero en general los beneficios de una microcápsula pueden acotarse a su tamaño pequeño, gran área superficial por volumen, grandes espacios internos, forma esférica y estabilidad para el transporte de sustancias químicas (Lakshmi, Figoli, Buonomenna, Colemme, \& Drioli, 2012), (Choi, et al., 2005), (Wang, Zhao, Wang, \& Gao, 2006), (Shchukin \& Sukhorukov, 2004).

Hay retos inherentes a la administración de fármacos y visualización en el cuerpo humano que pueden ser solucionados con microcápsulas. Por ejemplo, la ruta oral ha sido la principal vía para proveer tratamiento a 
cualquier enfermedad crónica, sin embargo como el $40 \%$ de los fármacos son lipófilos y dado a que la biodisponibilidad oral es baja, hay una gran variación en las respuestas de los pacientes (no hay una dosis proporcional) (Waterbeend, Dennis Smith, \& Walker, 2001). Para éstos fármacos, la tasa de adsorción en el lumen digestivo está controlada por disolución. Si se puede modificar las propiedades fisicoquímicas del compuesto, como la reducción de tamaño, se puede mejorar la taza de adsorción del lumen digestivo. De igual forma, si se opta por la vía intravenosa, las mismas deben ser menor a $250 \mu \mathrm{m}$ en diámetro (el caso ideal es menor de $125 \mu \mathrm{m}$ ) para que se puedan usar inyecciones (Benita, 2006). Si los fármacos son suministrados empleando microcápsulas, las dificultades enunciadas pueden ser superadas (Kumar, et al., 2011).

Otro gran reto que las microcápsulas pueden resolver es la pobre estabilidad de las burbujas dentro del cuerpo humano. Las burbujas son efectivas como agentes de contraste de ultrasonido, pero para ser usadas necesitan ser estables. Para funcionalizar la burbuja, polímeros pueden ser empleados para cubrirlas y estabilizarlas (convirtiéndose en una microcápsula). Las microcápsulas que están destinadas a ser agentes de contraste de ultrasonido deben medir entre 1-4 $\mu \mathrm{m}$ para recorrer con facilidad el circuito capilar y asegurar una prolongada circulación antes de que lleguen al hígado (Narayan \& Wheatley, 1999), (Lathia, Leodore, \& Wheatley, 2004), (Lin, Eckersley, \& Hall, 2009).

La idea de una microcápsula no es novedosa puesto que ya existían en la naturaleza estructuras vesiculares y micelas. En el cuerpo humano, las bicapas lípidas son estables porque la afinidad del agua con los enlaces de hidrógeno mantiene la membrana estable (Rave \& Johnson, 2001). Sin embargo, la desventaja que poseen es que la interacción entre las moléculas lípidas es débil por lo que la capa se desintegraría eventualmente (Daiguji, Takada, Molino, \& Takemura, 2009); aparte de que los lípidos no son un material adecuado para aplicaciones ingenieriles. Pero, con el desarrollo de nuevas técnicas, microcápsulas que son biocompatibles así como microcápsulas que se pueden emplear en diferentes situaciones ingenieriles pueden ser creadas.

\section{Microcápsulas vacías para aplicaciones de ultrasonido}

En general, las microcápsulas vacías se consideran como estructuras llenas de gas o agua. Esto se debe a que muchos investigadores denotan como vacía aquella estructura que posee un espacio interno lleno de un fluido. Sin embargo en este documento denotamos como vacías aquellas cuyo interior es un gas (CO2, N2, perfluorocarbonos 'PFC's") encapsulado en una cubierta polimérica delgada. (Lakshmi, Fioli, Buonomenna, Golemme, \& Drioli, 2012), (Schutt E. , Klein, Mattrey, \& Riess, 2003), (Kawahashi \& Matijevic, 
1991), (Preparation of hollow polylactide microcapsules through premix membrane emulsification-Effects of nonsolvent Properties, 2008), (Bejerknes, Sontum, Smistad, \& Agerkvist, 1997), (Crotts \& Park, 1995), (Bertling, Blömer, \& Kümmel, 2004).

Los materiales para la encapsulación en el área de biomédica dependen, como se mencionó, de la aplicación. La cubierta de estas cápsulas vacías pueden ser hechas de liposomas (Fang, Lee, Shen, \& Huang., 2006), (Chaize \& Fournier, 2004), polimersomas (Meng, Zhong, \& Feijen, 2009), coloidosomas (Kim, Fernandez-Nieves, Nily Dan, MArquez, \& Weitz, 2007), hidrogel (Lawrence, Cai, Hu, Marquez, \& Dinsmore, 2007), polielectrolitos (Molino, Matsuoka, \& Daiguji, 2011), (Daiguji, Matsuoka, \& Muto, Fabrication of hollow poly-allylamine hydrochloride/poly-sodium styrene sulfonate microcapsules from microbubble templates, 2010), (Geest, et al., 2005), nano partículas inorgánicas (e.g. oro, titanio, sílica) (Wu, Yu, \& Chu, 2011), (Zhang, Li, Shao, \& Yuan, 2009), (Caruso, Hollow Capsule Processing through Colloidal Templating and Self-Assembling , 2000), (Liu \& Wilcox, 1995), melamina (Daiguji, Makuta, Kinoshita, Oyabu, \& Takemura, 2007), nano partículas lípidos, nano partículas ensambladas (Bagaria, Kadali, \& Wong, 2011), (Pardeike, Hommoss, \& Muller, 2009), goma (e.g. ácido algínico) (Zhao, Mao, Gao, \& Shen, 2006), celulosa (metilcelulosa), proteínas e inclusive carbohidratos (dextran, sacarosa).

En conclusión una microcápsula vacía es una burbuja estabilizada y por lo tanto también pueden ser usadas como agentes de contraste de ultrasonido.

Para entender la relevancia del proceso de encapsulación en aplicaciones de ultrasonido, es preciso comprender las propiedades y los retos del material que está siendo encapsulado: la microburbuja / gas.

La retro dispersión de un potenciador de eco de ultrasonido es proporcional al cambio de impedancia acústica entre la sangre y el gas que forma la burbuja. Dado a que esta impedancia es bien alta, la onda es completamente reflejada. Como la longitud de onda para diagnósticos está en el rango de 1-0.1 mm (1.5-15 MHz), lo que es más grande que el tamaño de la burbuja, las microburbujas se comportan como un dispersor Rayleight. La sección transversal de dispersión $\varphi$ para un dispersador linear cuya longitud característica es menor que la longitud de onda está dada por la siguiente ecuación:

$$
\phi=\left(\frac{4}{9} \pi R^{2}(k R)^{4}\right) \cdot\left(\left(\frac{\kappa_{s}-\kappa}{\kappa}\right)^{2}+\frac{1}{3}\left(\frac{3\left(\rho_{s}-\rho\right)}{2 \rho_{s}-\rho}\right)^{2}\right)
$$

donde $\mathrm{R}$ es el radio del dispersador, $\lambda$ es la longitud de onda, $\mathrm{k}=2 \pi / \lambda$ es el número de onda, $\mathrm{k}_{\mathrm{s}}$ es el factor de compresibilidad del dispersador, y $\mathrm{k}$ es el 
factor de compresibilidad de la fase contínua. De la ecuación se entiende que la sección transversal de dispersión aumenta en función de la diferencia de densidades y factores de compresibilidad. Por lo tanto, usar un gas como un agente de perfusión de contraste asegura una mayor sección transversal de dispersión (de Jong, Ten Cate, Lancee, Roelandt, \& Bom, 1991).

Sin embargo, es interesante notar que la reflexión por sí sola no es del todo efectiva para crear un contraste nítido puesto que las microburbujas son pocas en comparación con la sangre y el tejido. Por ello se emplean los armónicos de la microburbuja. A pesar de que la magnitud de los armónicos es más débil que la de la resonancia de la burbuja, es lo suficientemente fuerte y distinguible para hacer diagnósticos. Por lo tanto es posible distinguir con claridad entre el tejido circundante y la sangre. Esta imagen de harmónicos, mejor conocida como imagen en modo B, ofrece un gran cociente entre señal y ruido y permite obtener imagines claras aun cuando la velocidad del flujo es lenta (Plesset \& Sadhal, 1982).

El reto con el uso de micro burbujas es que tienen un periodo de vida muy corto en el sistema. La presión interna de la burbuja es el resultado de la presión de equilibrio (Ley de Henry), la presión de Laplace, y la presión del torrente sanguíneo y esto supera con creces la presión de solubilidad del gas en la sangre. En otras palabras, el gas se disuelve en la sangre. De hecho la presión de Laplace es el responsable principal para el movimiento de gas fuera de la burbuja. La caída de presión en la interface está dada por:

$$
\Delta p=p_{b}-p_{b}=\frac{2 \gamma}{r}
$$

En donde $\boldsymbol{r}$ es el radio de la burbuja, yes la tensión superficial y $\Delta \mathrm{P}$ es la diferencia de presión que experimenta la burbuja. A medida que el gas se difunde fuera de la burbuja, el radio se reduce y por lo tanto la presión interna en la burbuja incrementa y aumenta la velocidad de disolución de la burbuja. Recordemos que es crítico para una burbuja poseer un tamaño subcapilar para asegurar su recorrido en el circuito sanguíneo y permitir suficiente tiempo para realizar un diagnóstico adecuado (Plesset y Epstein calcularon que una burbuja de aire de $10 \mu \mathrm{m}$ demoraría en disolverse $1.17 \mathrm{sec}$ en agua que ha sido de-aireada y unos $6.63 \mathrm{sec}$ en un agua que está saturada de aire (Borden \& Longo, 2002)). Es crucial que las cápsulas tengan tamaños uniformes para optimizar la retrodispersión.

Una de las formas de hacerle frente a la inestabilidad de las burbujas es emplear perfluorocarbonos (PFCs). Es importante reducir el coeficiente de partición del gas (aire en los casos usuales) entre la fase líquida y la fase gaseosa (conocido como coeficiente de Ostwald, L). Esta reducción puede lograrse al añadir PFCs en las burbujas de aire. Para lograr este objetivo, la combinación de un bajo coeficiente de Ostwald (<104) y un valor alto para la 
presión de vapor a temperatura corporal $(>3 \cdot 104 \mathrm{~Pa})$ es necesaria (algunos PFCs presentan estas cualidades (Schutt E. G., Klein, Mattrey, \& Riess, 2003)). En otras palabras, como la mayor parte de la microburbuja estará conformada por PFCs, la concentración de aire es tan diluida que la presión parcial del gas más soluble (aire) es 1atm. Puede haber difusión de aire desde y hacia la burbuja y estos cambios de presión pueden ser soportados por el PFC. La Figura 1 es un esquemático que representa este fenómeno. (Schutt E. G., Klein, Mattrey, \& Riess, 2003).

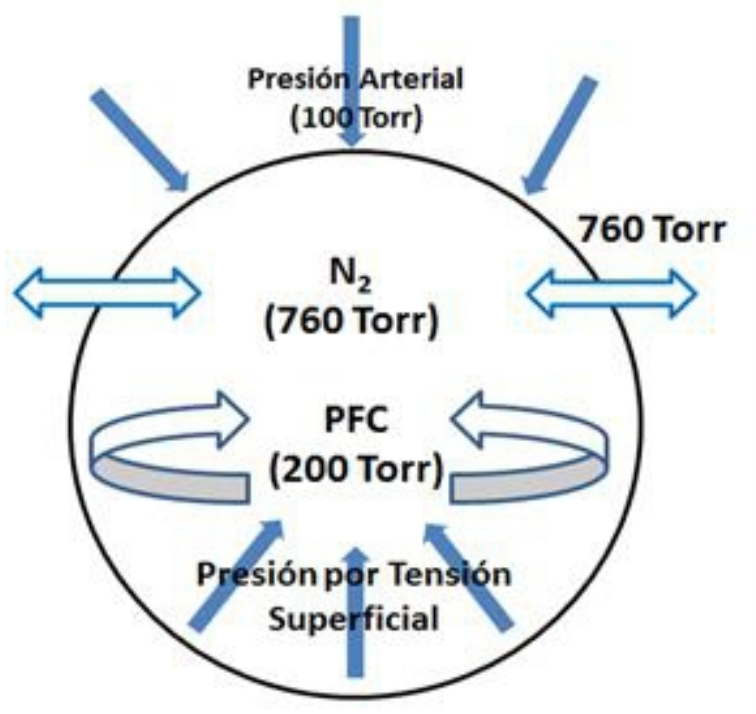

Figura 1: Equilibrio Osmótico. Un equilibrio osmótico se establece entre los gases solubles en la sangre, cuya presión parcial dentro de la micro burbuja se mantiene contante en 1atm, mientras que la presión parcial en el PFC ofrece un balance al efecto de la presión de la sangre y la presión de Laplace (Schutt E. G., Klein, Mattrey, \& Riess, 2003).

La segunda opción es cubrir al micro burbujas para que puedan ser usadas adecuadamente como agentes de contraste de ultrasonido. Es decir, encapsular a la burbuja. Existen varios tipos de agentes de contraste de ultrasonido que usan lípidos para proteger el micro burbujas. Ejemplos de estos productos son resumidos en la tabla 1 (Borden \& Longo, 2002).

La ecuación (3) (Borden \& Longo, 2002) (Shalaby, 1994) es una versión modificada de la ecuación de Epstein-Plesset para la vida de una microburbuja considerando la permeabilidad de la capa que la rodea.

$$
-\frac{d r}{d t}=\frac{L}{r / D_{w}+R_{\text {shell }}} \cdot\left(\frac{1+\left(2 \sigma_{\text {shell }} / P_{a} \cdot r-f\right)}{1+\left(4 \sigma_{\text {shell }} / 3 P_{a} \cdot r\right)}\right)
$$


Donde $\mathrm{L}$ es el coeficiente de Ortwald, $D w$ es la difusividad del gas en agua, $R_{\text {shell }}$ es la resistencia de la capa a permeación de gases, $f$ es la razón entre la concentración de gas y la concentración de saturación (i.e. $\mathrm{f}=1$ es para un estado saturado), $P_{a}$ es la presión atmosférica and y $\sigma_{\text {shell }}$ es la tensión superficial en la interface gas-líquido.

Tabla 1: Agentes de contraste a base de microburbujas

\begin{tabular}{|c|c|c|c|}
\hline Nombre Comercial & $\begin{array}{l}\begin{array}{l}\text { Material de la capa } \\
\text { (Rigidez) }\end{array} \\
\end{array}$ & Gas (solubilidad) & Tamaño $(\mu \mathrm{m})$ \\
\hline Albumex & Albumina (Alta) & Aire (Alta) & 4.3 \\
\hline Optison $^{\mathrm{TM}}(\mathrm{FS} 069)$ & Albumina (Alta) & Octafluorpropano (Baja) & 4.5 \\
\hline MP1950 & Lípido (Baja) & Decafluorobutano (Baja) & 2.0 \\
\hline PESDA & Albumin NA & Decafluorobutano (Baja) & 4.7 \\
\hline $\begin{array}{l}\text { Definity®(MRX- } \\
115)\end{array}$ & $\begin{array}{l}\text { Lípido/surfactant } \\
\text { (Baja) }\end{array}$ & Octafluorpropano (Baja) & $1.1-3.3$ \\
\hline $\begin{array}{l}\text { Imagent(AFO- } \\
150)\end{array}$ & $\begin{array}{l}\text { Lípido/surfactant } \\
\text { (Baja) }\end{array}$ & $\begin{array}{l}\text { Nitrogen/perfluorohexane } \\
\text { (Baja) }\end{array}$ & 6.0 (mediana) \\
\hline Sonovue $₫(B R-1)$ & Lípido (Baja) & Sulfur hexafluoride (Baja) & 2.0 (mediana) \\
\hline BR14 & Lípido (Baja) & Perfluorobutane (Baja) & 2.6 \\
\hline $\begin{array}{l}\text { Levovist } \\
\text { 508A) }\end{array}$ & $\begin{array}{l}\text { Lípido/Galactosa } \\
\text { (Baja) }\end{array}$ & Aire (Alta) & $2.0-4.0$ \\
\hline $\begin{array}{l}\text { biSphere }^{\mathrm{TM}} \\
\text { (PB127) }\end{array}$ & $\begin{array}{l}\text { Poliláctido/albúmina } \\
\text { (Alta) }\end{array}$ & Nitrógeno (Alta) & 3.0 \\
\hline $\begin{array}{l}\text { Sonazoid } \\
(\mathrm{NC} 100100)\end{array}$ & $\begin{array}{l}\text { Lípido/surfactante } \\
\text { NA }\end{array}$ & Perfluorobutano (Baja) & 2.2 \\
\hline ST68-PFC & Lípido/surfactante L & Decafluorobutano (Baja) & 1.8 \\
\hline $\begin{array}{l}\text { Sonavist } \\
\text { (SHU563a) }\end{array}$ & Cianoacrilato (Alta) & Aire (Alta) & NA \\
\hline
\end{tabular}

Esta ecuación asume una burbuja de forma esférica. Adicional a esto, la ecuación (3) no contempla el deterioro de la capa y tampoco los cambios producto del tamaño del núcleo a medida de que el aire se va permeando, sin embargo proveen información útil y tangible a cerca del problema de la disolución. La Figura 2 muestra la dinámica de disolución de una burbuja a partir de la ecuación (3). De esta gráfica obtenemos información importante sobre la necesidad de emplear una capa impermeable y el comportamiento de los PFCs. 

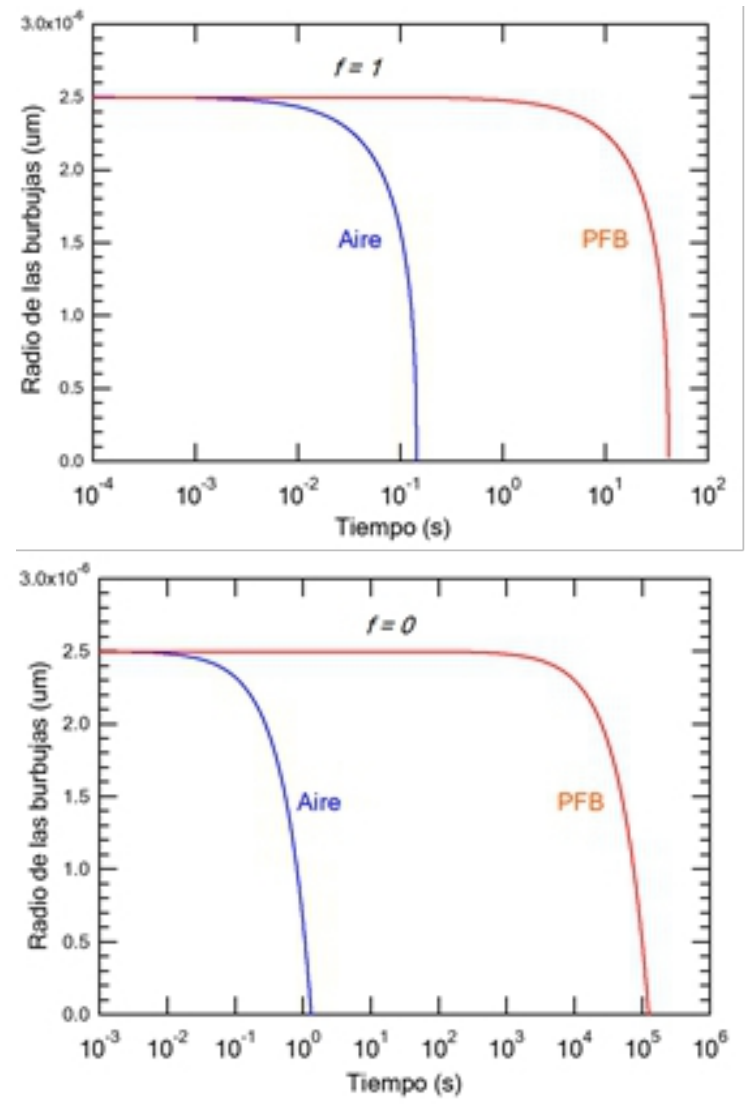

Figura 2: Dinámica de disolución. Dinámica de solución calculada a partir de la ecuación ecuación Epstein-Plesset modificada. (Izquierda) Curvas de radio vs tiempo para una microburbujas compuesta de aire o perfluorobutano (PFB). Los parámetros para el modelo fueron $\sigma_{\text {shell }}=72 \mathrm{mN} \mathrm{m}^{-1}, R_{\text {shell }}=0, P a=101.3 \mathrm{kPa}, \mathrm{y} f=1$ (i.e., saturación). Los parámetros de difusión para el aire fueron $\mathrm{L}=0.02 \mathrm{y} \mathrm{Dw}=2 \times 10-5 \mathrm{~cm} 2 \mathrm{~s}^{-1}$; aquellos para PFB fueron

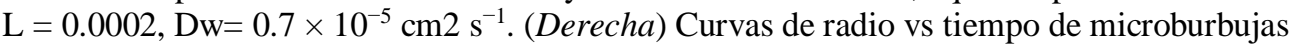
cubiertas con lípidos en agua que ha sido de gasificada $(f=0)$. Los parámetros del modelo fueron los mismos que los de arriba, excepto que $R_{\text {shell }}=104 \mathrm{~s} \mathrm{~m}^{-1}$ para aire y $107 \mathrm{~s} \mathrm{~m}^{-1}$ para PFB y $\sigma_{\text {shell }}=0 \mathrm{mN} \mathrm{m}^{-1}$.

Los resultados de la figura 2 pueden ser resumidos de la siguiente manera: para una vida útil de días o inclusive meses, la cubierta debe ser sólida para poder eliminar la tensión superficial y reducir la permeabilidad del gas a través de la cubierta. Una cubierta sólida impermeable elimina el problema de la presión de Laplace, que es la causante de la disolución "instantánea" del aire, pero recordemos que dicha capa debe ser lo suficientemente delgada y flexible para permitir que la burbuja oscile. He de allí la importancia del microencapsulación. 


\section{Técnicas para la fabricación de microcápsulas}

A pesar de que existen muchas técnicas para la fabricación de microcápsulas vacías, en general todas se pueden categorizar en cuatro métodos principales: métodos químicos, métodos físico-químicos, métodos electro-químicos y métodos físico-mecánicos. Dentro de los métodos químicos, el método de polimerización interfacial es el más popular. En ésta técnica la cubierta de la cápsula es el resultado de una reacción entre el polímero y la superficie de una gota o una partícula sólida que está siendo usada como núcleo. En muchos casos, monómeros multifuncionales, i.e. isocianatos, son dispersados en los núcleos líquidos, que están suspendidos en una emulsión. Otro polímero reactivo multifuncional (e.g. amino) es dispersado en la fase contínua y esto permite que se dé una reacción entre los dos polímeros en la interface del núcleo y la fase contínua (polimerización), luego que una capa se ha formado alrededor del núcleo. Luego de que estos son removidos se obtiene una microcápsula vacía. El proceso de polimerización también puede ocurrir sobre la superficie de una burbuja, y por lo tanto una microcápsula vacía puede ser creada en un simple paso (Daiguji, Makuta, Kinoshita, Oyabu, \& Takemura, 2007), (Saihi, Vroman, Giraud, \& Bourbigot, 2006), (Feng, Wang, Gao, \& Shen, 2007).

Entre los métodos físico-químicos está el método de coacervación o el de separación de fases. Coacervación es un fenómeno coloidal donde un polímero homogéneo se desolva parcialmente de una solución polimérica homogénea y da como resultado una fase rica en polímero (coacervato) y una fase pobre en polímero. (Narayan \& Wheatley, 1999) (Ghosh, 2006) Este método consiste de tres pasos que se ejecutan mientras se agita la solución continuamente: 1 . Tres fases inmiscibles se forman, 2. El material para crear la cubierta es depositado en la solución, y 3. La cubierta se solidifica. (Shun Li, Feld, \& Grim, 1988) (Shalaby, 1994)Esto se puede apreciar en el esquemático de la figura 3.

Una técnica común dentro de los métodos electroquímicos es el método de Capa por Capa (LBL por su nombre en inglés "Layer by Layer Method"). Con este método se pueden crear microcápsulas hechas de polielectrolito y la misma se caracteriza por sus interacciones no covalentes entre las cadenas de polímero. Así se puede sintetizar capas en el orden de los nanómetros alrededor de los núcleos al adsorber secuencialmente polianiones y policationes. (Zhao, et al., 2007) (Decher, 1996) (Knoll, 1996) La adición secuencial de polielectrolitos requiere una proporción de masa (cociente entre policationes y polianiones) adecuada de lo contrario la formación de agregados irreversibles incrementa (Park, Choi, Kim, Chung, \& Sohn, 2008), (Peyratout \& Dahne, 2004). 


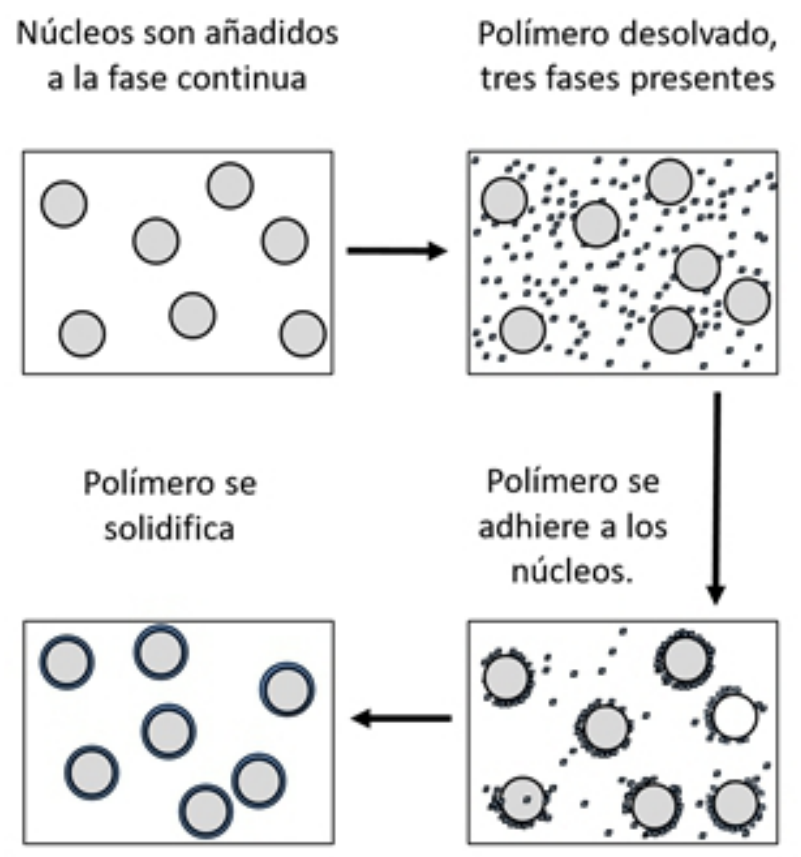

Figura 3: esquemático del proceso de coacervación

En cuanto a procesos físico-mecánicos, el método de evaporación de solvente es el más popular. En este método una emulsión de agua/aceite/agua $(\mathrm{W} / \mathrm{O} / \mathrm{W})$ o aceites/agua $(\mathrm{O} / \mathrm{W})$ es creada: núcleos (gotas) hechas de una solución de polímeros disueltos en un líquido (fase de aceite, e.g. diclorometano) y estos a su vez son añadidos a una fase contínua (fase de agua, e.g. solución de alcohol de polivinilio) y mezclados vía agitación mecánica. De esta manera se crea una emulsión. La mezcla es calentada y agitada hasta que todo el solvente se evapora y el polímero se sobresatura en la interface agua/aceite formando una capa (Narayan \& Wheatley, 1999).

Dependiendo del núcleo empleado, luego de que la capa ha sido formada, la permeabilidad y fortaleza de la cubierta son degradas intencionalmente a través de disolución, evaporación o termólisis (e.g. calcinación y liofilización), y así obtener microcápsulas vacías.

El único detalle con todas estas técnicas es que es difícil de controlar todas las propiedades de interés en una microcápsula. Por ejemplo, es difícil controlar la fortaleza mecánica, permeabilidad, porosidad, biocompatibilidad y uniformidad usando un solo proceso. A través de las técnicas discutidas no puede ser logrado puesto que la fabricación de las cápsulas, no solo dependen del proceso; sino también de las propiedades físico químicas del material que se está empleando.

A continuación, se explican ciertas técnicas para fabricar microcápsulas vacías para aplicaciones biomédicas. Este documento se enfoca 
en las más prometedoras fundamentándonos en su simplicidad y capacidad de escalamiento para producción en masa. Las cinco técnicas son CAN-BD, LbL, atomización electrohidrodinámica, microfluídos y evaporación de solvente.

\section{Fluidos supercríticos: CAN-BD}

Recientemente, se han desarrollado muchas técnicas que emplean fluídos supercríticos. El interés procede del hecho que esta técnica tiene la ventaja de que el residuo del solvente orgánico es mínimo por lo que el proceso de purificación (limpieza) de las cápsulas es más fácil. Adicional a esto, el producto final es suficientemente uniforme, el proceso de fabricación toma segundos y dado a que opera a bajas temperaturas, componentes activos sensibles a la temperatura pueden ser cargados a la capsula (Benita, 2006).

Un fluido es supercrítico cuando su presión y temperatura están por arriba de la presión crítica (Pc) y la temperatura crítica (Tc) respectivamente.

En la región supercrítica, las propiedades del fluido supercrítico pueden ser controladas (e.g. viscosidad, difusividad, tensión superficial). Esto implica que las propiedades pueden ser controladas para adaptarse a diferentes necesidades. Por ejemplo, si la tensión superficial y la viscosidad son controlables, el tamaño de las gotas atomizadas también lo es. Por lo general, $\mathrm{CO}_{2}$ es el fluido supercrítico más empleado porque posee puntos críticos bajos $\left(\mathrm{P}_{\mathrm{c}}=73.8 \mathrm{~atm}\right.$ y $\left.\mathrm{T}_{\mathrm{c}}=31.1 \mathrm{C}\right)$, es asequible $\mathrm{y}$, también es considerado como seguro. Adicional a esto, $\mathrm{CO}_{2}$ es no polar, por lo que no puede disolver compuestos lipofílicos o hidrofílicos (la mayoría de los compuestos farmacéuticos son lipofílicos o hidrofílicos) pero puede disolver sustancias lipofílicas que posean un peso molecular bajo, lo que convierte al $\mathrm{CO}_{2}$ en solvente y no solvente para muchas aplicaciones farmacéuticas.

CAN-BD puede ser clasificada dentro de las técnicas de fluidos súper críticos (SCF). El acrónimo procede del inglés Carbon Dioxide Assisted Nebulization with Bubble Dryer (Nebulización asistida por dióxido de Carbono con Secador de Burbuja). Es mismo es un proceso físico químico y consiste en la nebulización de una solución líquida que contiene un soluto formado por micro-nano partículas que se precipitan a medida que el solvente es extraído. En otras palabras, la solución supercrítica, que contiene un cosolvente y polímeros disueltos (material para la capa), se mantiene a alta presión y luego atomizado a través de una tobera o capilar en una recámara que se encuentra a presión atmosférica. La expansión rápida da como resultado una especie de aerosol que está formado por microgrotas y microburbujas. De esta manera microcápsulas vacías pueden ser obtenidas a través de este proceso. Este atomizado es dirigido a una recámara de secado que contiene nitrógeno o aire caliente que mantiene una temperatura deseada durante el proceso. Las partículas producidas son recolectadas al final de la recámara. El tamaño de los poros en los filtros está entre los 0.2 y $0.45 \mu \mathrm{m}$. El flujo típico 
en el laboratorio está entre 0.3 to $0.6 \mathrm{ml} / \mathrm{min}$. El proceso ha sido escalado proporcionalmente por Sievers et al (Sievers, et al., 2007) y ha podido usar flujos tan altos como $30 \mathrm{ml} / \mathrm{min}$, lo que lo ubica en escala de producción masiva para la fabricación de productos farmacéuticos de gran valor (Thiering, Dehghani, \& Foster, 2001). Un esquemático de este proceso es mostrado en la Figura 4.

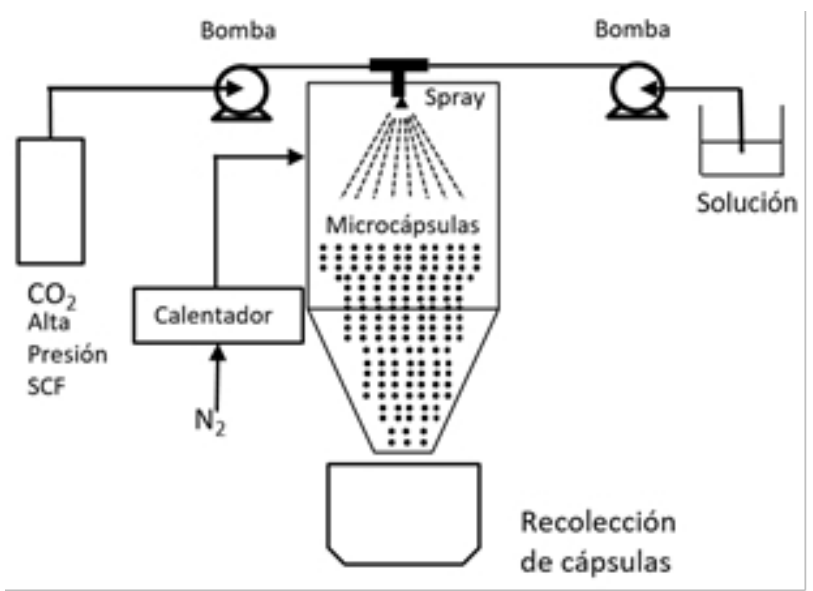

Figura 4: Esquemático de CAN-BD

CAN-BD ha sido empleado eficientemente para cargar vacunas. Se ha alcanzado una retención de actividad biológica del antígeno para la Hepatitis B (HBsAg) (Sievers, et al., 2007) así como también se ha logrado cargar cápsulas con el virus del meningitis de forma efectiva a través de esta técnica (Sievers, et al., 2007).

Adicional a esto, una vacuna liofilizada de meningitis ha sido encapsulada usando CAN-BD y suministrada por la vía pulmonaria (vacuna seca) y se ha concluido que $107 \pm 23$ de la actividad viral ha sido preservada.

Cape et al. (Cape, et al., 2008) reportó haber producido un pulverizado seco del anticuerpo anti-CD4, que es un anticuerpo monoclonal con el potencial valor clínico de tratar la artritis reumatoide. Por supuesto que CANBD ha sido empelada para cargar cápsulas con ibuprofeno.

CAN-BD ofrece una descomposición mínima de medicamentos que son afectados por el calor ya que las temperaturas operacionales del proceso son más bajas que otros métodos que emplean la extracción de solvente para fabricar cápsulas. La cápsula final tiene un tamaño menor a los tres micrómetros, lo que la hace ideal para su administración pulmonaria (como se había mencionado). (Parhi \& Suresh) La Figura 5 muestra una imagen de SEM de microcápsulas cargadas con anticuerpos anti-CD4. 


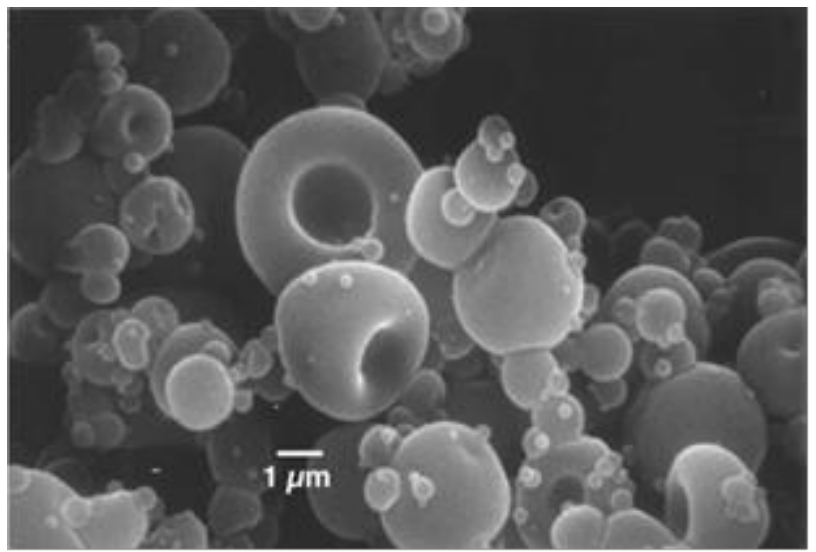

Figure 5: Anticuerpo Anti-CD4. Imagen SEM de partículas de anticuerpos anti-CD4 producidas a través de CAN-BD (Cape, et al., 2008).

\section{Electroatomización coaxial}

Electro atomización o electro atomización hidrodinámica (EHDA) es un proceso empleado para hacer gotas aplicando un potencial de varios miles de voltios entre una placa y la punta de un capilar de donde líquido está emanando. El tamaño de la gota final, dependiendo de las condiciones de fabricación, puede ser en el rango milímetros a tamaños submicrométricos (Chang, Stride, \& Edirisinghe, Controlling the thickness of hollow polymeric microspheres prepared by electrohydrodynamic atomization, 2010). La técnica se remonta al año 1915 a través del trabajo realizado por Zeleny, Vonneguton y Neubauer en aerosoles (Zeleny, 1915), (Vonnegut \& Neaubauer, 1952). Sin embargo, fue hasta hace poco que Chang et al (Chang, Stride, \& Edirisinghe, Controlling the thickness of hollow polymeric microspheres prepared by electrohydrodynamic atomization, 2010) (Chang, Edirisinghea, \& Stride, Ultrasound mediated release from stimuli-responsive core-shell capsules, 2013) y Zhang et al (Zhang, et al., 2012) emplearon EHDA para fabricar de manera efectiva microcápsulas vacías con tamaños y espesor de cubierta ajustable. Chang et al empleó perfluorohexano (PFH) como una plantilla (partícula o núcleo) y un polímero biocompatible polimetilsilésquixano (PMSQ) como el material de la capa. Las soluciones fueron suplidas usando una micro jeringa. PFH fue suministrado con una jeringa de $150 \mu \mathrm{m}$ y PMSQ fue suministrado con una jeringa de $300 \mu \mathrm{m}$ de diámetro. Las agujas son concéntricas, la interna es PFH y la externa es PMSQA, esto dá como resultado una estructura de un nucleo de PFH con una cubierta de PMSQA. En el experimento, PFH fue suplido a una tasa de $150 \mu 1 / \mathrm{min}$ y PMSQ fue suplido a una de $650 \mu \mathrm{L} / \mathrm{min}$. En el caso de Zhang et al, se produjeron cápsulas vacías usando polietersulfona (PES) disuelta en dimetil sulfóxido (DMSO) que es el material de la cubierta. Para el núcleo 
emplearon PVA (ácido de polivinil) y PEG (polietilen glicol) en DMSO. Un esquemático general de EHDA es mostrado en el panel ' $a$ ' de la figura 6.

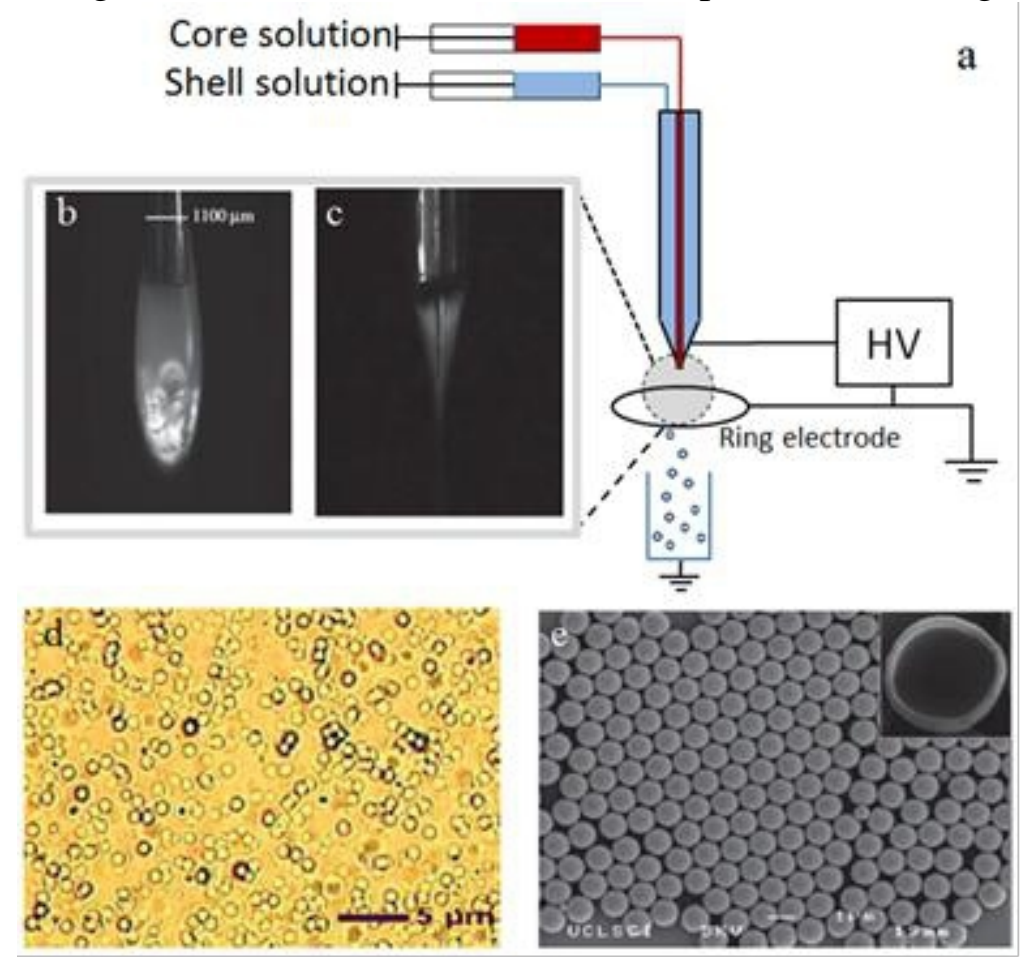

Figura 6: Microcápsulas de EHDA. (a) El montaje del experimento; (b) goteo y (c) comportamiento estable del jet de PMSQ/PFH, (c) Imagen de campo brillante microcápsulas vacías inmediatamente después de la fabricación y (d) imagen SEM de las microcápsulas con una imagen en la esquina del área transversal de la cavidad vacía (Chang, Edirisinghea, \& Stride, Ultrasound mediated release from stimuli-responsive core-shell capsules, 2013), (Chang, Stride, \& Edirisinghe, Controlling the thickness of hollow polymeric microspheres prepared by electrohydrodynamic atomization, 2010).

El proceso se beneficia de las diferencias en solubilidades y volatilidad de los líquidos que están siendo empleados. En general, la aceleración del flujo externo está dominada por el campo eléctrico, mientras que el flujo interno está dominado por los estreses viscosos, por lo que el flujo debe ser ajustado para que ambos fluidos viajen a la misma velocidad. El proceso de formación de las cápsulas vacías a través de EHDA es especial (Pisani, et al., 2006) (Chang, Stride, \& Edirisinghe, Controlling the thickness of hollow polymeric microspheres prepared by electrohydrodynamic atomization, 2010) dado a que para remover los núcleos o el núcleo (que son hidrosolubles) las cápsulas se depositan en agua luego de su fabricación, de manera tal que el núcleo hidrófilo pueda ser removido. También los mismos pueden removerse aumentando la temperatura puesto que el punto de ebullición es bajo. En general todas las cubiertas tienen nano poros que permiten el transporte de gas 
o líquido del interior al exterior. Se ha reportado que con esta técnica también se pueden obtener materiales altamente porosos.

El método de EHDA puede ser empleado también para aplicaciones ingenieriles aunque la cantidad producida sigue siendo muy limitada. La ventaja de EHDA es que varias jeringas pueden ser empleadas como una manera eficiente de producir en masa y desarrollar microcápsulas con diferentes propiedades (capas dobles hechas de diferentes materiales) (Hwang, Jeong, \& Cho, 2008), (Kim \& Kim, 2010).

Otra gran ventaja de EHDA es que se pueden producir partículas mono dispersas. Como se mencionó previamente, las aplicaciones farmacéuticas requieren partículas con un mismo tamaño, y dado a que la velocidad de remoción del solvente es lenta, eso mantiene la integridad de la cápsula ( $\mathrm{Si}$, et al., 2012) (Parhi \& Suresh) (Benita, 2006).

\section{LBL: Plantillas biológicas y de burbujas}

Usualmente las cápsulas vacías de polielectrolito se obtienen a través de la descomposición del núcleo de la cápsula luego de la formación de la capa de electrolito a través del método LBL. La formación de esa capa se lleva a cabo a través de la adsorción de capas de (Bertrand, Jonas, Lashewsky, \& Legras, 2000), (F. Caruso, 1998), (Caruso, Lichtenfield, Giersig, \& Mohwald, 1998), (Yin, Lu, Gates, \& Xia, 2001) de poliectrolitos cargados a una partícula coloidal (el núcleo). La adsorción secuencial de polielectrolitos de cargas opuestas permite crear capas de un espesor deseado y la fortaleza de la adsorción depende de la fuerza iónica (Korneev, Lvov, G.Decher, Schmitt, \& Yaradaikin, 1995), (Dubas \& Schlenoff, 1999), temperatura, y pH (Shchukin, Köhler, Möhwald, \& Sukhorukov, 2005). La fuerza que domina la adsorción secuencial es la atracción electrostática entre las especies que poseen cargas opuestas. Por esta razón, el sistema es estable contra la desorción, pero dado a que las interacciones individuales son débiles, la estructura final de la capa depende grandemente de las condiciones de fabricación. Las plantillas o partículas empleadas para el núcleo pueden ser diversas, pero se evitan aquellas líquidas (gotas) puesto que representan un reto para la adosrción de estos polielectrolitos y la polidispersidad de los núcleos no es uniforme, por lo que núcleos sólidos son preferidos para LBL. Cuando núcleos líquidos son empleados, usualmente se usan vesiculas o gotas emulsificadas (Park, Oh, Shin, Moon, \& Oh, 2003) (McKelvey, Kaler, Zasadzinski, Coldren, \& Jung, 2000). Hasta hace poco aire y células son empleadas como núcleos (NEU, et al., 2001). En cuanto a la capa, silica, oro, y zinc son empleados. (Imhof, 2001), (Xu \& Asher, 2004), (Wu, Yu, \& Chu, 2011), (Zhang, Li, Shao, \& Yuan, 2009). La figura 7 muestra un esquemático del método de capa por capa (LBL). Casi cualquier capa de polieletrolitos puede ser empleada para formar una microcápsula, lo que convierte esta técnica en una de las más versátiles 
para la fabricación de microcápsulas. La remoción de los núcleos es llavada a cabo a través de unos de los métodos previamente descritos (e.g. termólisis, liofilización).

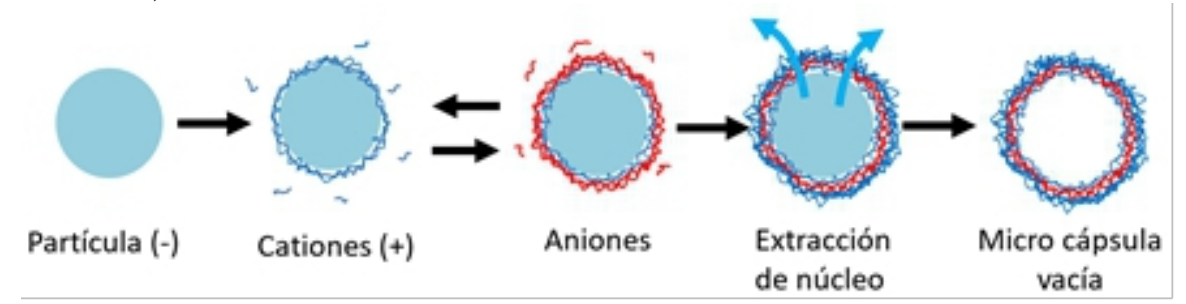

Figura 7: Método de capa por capa.

Adsorción secuencial de contra iones permite la formación de una capa.

A pesar de que es fácil fabricar una microcápsula vacía usando este método, sería mucho más conveniente si se pudiera eliminar el proceso de remoción de los núcleos, es decir, si se pudiera adsorber directamente a una burbuja. Inclusive, la técnica sería aún más ventajosa si se pudiera emplear cualquier núcleo y de cualquier forma.

\section{Nucleos de Burbuja}

Recientemente Shchukin et al. (Shchukin, Köhler, Möhwald, \& Sukhorukov, 2005) desarrolló una técnica para sintetizas microcápsulas vacías usando microburbujas como núcleos. En estos experimentos, microburbujas fueron generadas via sonicación en una solución de tween/spam. Dado a que la superficie de la burbuja estaba cargada como resultado de la adición del tween/spam, esto permitió la adsorción secuencial de PAH (cloridrato de polialilamina) y PSS (poli estireno sulfonato de sodio). Un esquemático del procedimiento es mostrado en la Figura 8.

Adicional a esto, a través del trabajo de Daiguji et al (Daiguji, Matsuoka, \& Muto, 2010) se demostró que microcápsulas vacías de PAH se puenden fabricar con facilidad a partir de microburbujas sin la necesidad de surfactantes. En una solución de $\mathrm{Na}_{2} \mathrm{CO}_{3}$, dentro de un rango de $\mathrm{pH}$, PAH se descompone en las partículas coloidales de ion carbamato (R-NHCOO-) y el ion amino $\left(\mathrm{R}_{-}-\mathrm{NH}_{3}{ }^{+}\right.$). Cuando burbujas de $\mathrm{CO}_{2}$ son nucleadas en la solución, las partículas coloidales de PAH estabilizan las microburbujas via adsorción. Sin embargo, estas cápsulas solo son estables a un $\mathrm{pH}=8.5$. Molino et al. (Molino, Matsuoka, \& Daiguji, 2011) usó el mismo método mencionado y logró controlar el radio de las cápsulas al cambiar la concentración de $\mathrm{Na}_{2} \mathrm{CO}_{3}$ y elucidaron las condiciones requeridas para sintetizar una cápsula vacía estable de dos capas y los requisitos para poder tener una microcápsula vacía de PAH-PSS estable a un $\mathrm{pH}=7.0$. 


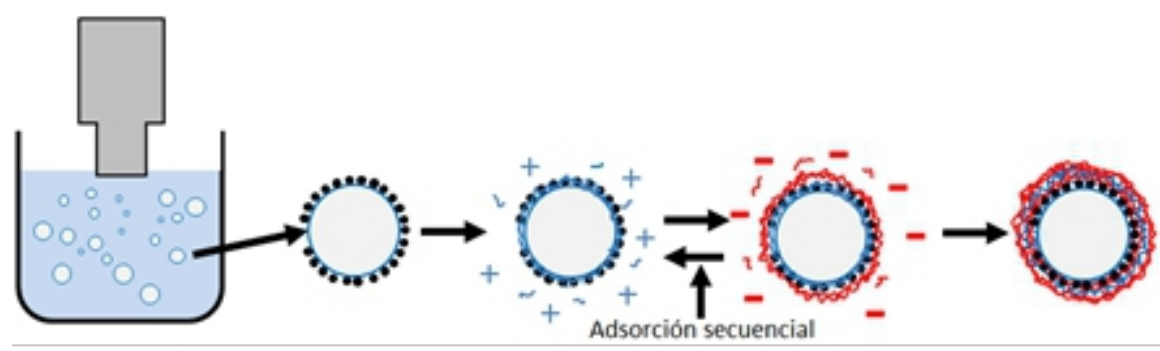

Figura 8: LbL-núcleo de microburbuja creada vía sonicación. La síntesis de microcápsulas vacías usando micro burbujas que fueron generadas en una solución de tween-spam. Tween-

span estabiliza las burbujas y permite la adsorción secuencial de contra iones sobre la superficie de la burbuja. El resultado es una microcápsula biodegradable vacía. (Shchukin,

Köhler, Möhwald, \& Sukhorukov, 2005)

\section{Bioplantillas-bionucleos}

Las ventajas de emplear estructuras biológicas como núcleos es que existen una gran variedad de formas que pueden ser logradas sin la necesidad de cambiar los procesos de producción o diseñar núcleos que posteriormente serán sacrificados. A menos que un núcleo sólido se use, es muy dificil de conseguir formas diferentes a esferoides dado a que es una esfera la forma de menor estado energético para una gota o burbuja que se puede emplear como un núcleo. La encapsulación de biomoléculas y organismos vivos tiene múltiples aplicaciones en el campo de biomédica y por lo tanto el entendimiento de la encapsulación de estos cuerpos es de gran relevancia.

Neu et al (NEU, et al., 2001) logro usar una célula roja (RBC) como un núcleo para crear una cápsula, asi como también logró removerla y crear una microcápsula vacía. En ese estudio, diez capas fueron depositadas sobre una RBC y una bacteria, respectivamente. Empleando una solución de $140 \mathrm{mM}$ de $\mathrm{NaCl}$ y $1.2 \%$ de $\mathrm{NaCl}$, lograron disolver la proteína y lípidos celulares. En este trabajo se concluye que la desventaja de emplear núcleos biológicos es la baja estabilidad de la membrana.

Adicional a esto, si se deseara modificar la superficie celular, entonces la preservación de la célula es imperativa. Sin embargo, se ha probado que los efectos citotóxicos dependen de la exposición de la célula a la concentración del policatión y la duración de la exposición dado a que los policationes inducen la formación de poros en la membrana celular como fue sugerido por Vladimir y Srikanth (Tsukuk \& Singamaneni, 2012).

\section{Microfluídicos}

Desde que se desarrolló el dispositivo de microfluídico (Thorsen, Roberts, Arnold, \& Quake, 2001) muchos investigadores han refinado el diseño de los equipos empleados para microfabricación y con estos, se han producido diferentes clases de partículas para diferentes propósitos. La ventaja del uso de microfluídicos radica en que pueden producir microcápsulas 
monodispersas (partículas sólidas también pueden ser fabricadas). A pesar de que otras técnicas como polimerización interfacial, coacervación, o secado por atomización pueden producir microcápsulas casi monodispersas, las propiedades de las cápsulas producidas son determinadas empíricamente dado a que cada parámetro de fabricación contribuye a la morfología de la cápsula final. De hecho uno de los retos a los que se enfrentan estas técnicas radica en que el producto fabricado no es realmente monodisperso. Si el tamaño no es uniforme, las propiedades mecánicas, resonancia y tasas de dosificación tampoco lo son. Sin embargo, con dispositivos microfluídicos, las cápsulas son fabricadas una por una y por lo tanto se puede obtener un gran control (Shingo Okushima, torii, \& Higushi, 2004) (Nie, Xu, Seo, Lewis, \& Kumacheva, 2005) (Seo, et al., 2005).

Un dispositivo microfluídico se caracteriza por un flujo laminar que facilita el análisis del comportamiento del fluido en el dispositivo. Es fácil de confeccionar el dispositivo micro fluídico. Un esquemático de micro fluidos se muestra en la figura 9. En la figura, el fluido A será empleado para el núcleo de la cápsula. El mismo puede ser una fase de aceite, mientras que el fluido B puede ser una fase de agua y el fluido $\mathrm{C}$ una de aceite lo que da como resultado una emulsión de aceite en agua en aceite (O/W/O) (Wei, et al., 2011). Las soluciones pueden variar a W/O/W. El punto importante de esta fabricación es que la fase intermedia (e.g. el fluído B en la imagen) es poco o no miscible en el fluido A o C. Luego de la fabricación, los núclos son removidos.

Choi et al. (Choi, Jung, Kim, Chungc, \& Lee, 2008) desarrolló un método de un solo paso para preparar micro cápsulas vacías termo sensibles hechas de poli (N-isopropilacrilamida) (PNIPAM). Esta fue la primera vez en la cual se han producido microcápsulas termo sensible. Choi et al reportó que usaron fotolitografía y una mezcla de PDMS y agentes de curado para construir el dispositivo micro fluídico.

Para obtener micro cápsulas vacías, gotas de una solución acuosa que contiene un monómero son introducidas en la fase continua, la misma posee un fotoiniciador que es soluble en la fase de aceite. Al irradiar las gotas con UV, el proceso de polimerización inicia en la interface de la solución acuosa y la fase de aceite. El aspecto primordial de este proceso es que al ser irradiada con UV, las cápsulas se hacen vacías lo que representa una gran ventaja comparado a otros estudios (Kim, Utada, Fernández-Nieves, Hu, \& Weitz, 2007) donde potentes solventes son empleado para remover los núcleos. Las cápsulas fabricadas por Choi et al fueron confirmadas que eran vacías usando frezado de haz de iones.

En un estudio diferente, Zhang et al (Zhang, et al., 2013) diseñó hidrogeles de respuesta a la glucosa a largo plazo (Poli (ácido N isopropilacrilamida - ácido co - 3 - aminofenilborónico - ácido co - acrílico) (PNA) para fabricar microcápsulas vacías usando dispositivos microfluídicos. 


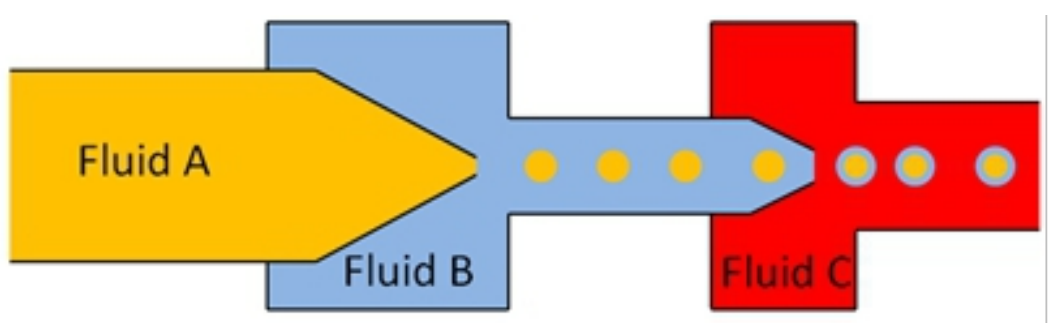

Figura 9: Esquemático general de un dispositivo microfluídico- dispositivo capilar

En general, los hidrogeles responden a diferentes condiciones dentro del cuerpo humano (cambios de temperatura, $\mathrm{pH}$, y salinidad). La manera de fabricar estas microcápsulas es la misma que la mostrada en la figura 9 . Zhang et al también empleó UV para iniciar la polimerización y así fabricar microcápsulas vacías. En el estudio, analizaron el efecto de la concentración de la glucosa en la hinchazón de la cápsula fabricada. Las microcápsula de PNA se hincharon ante la presencia de glucosa, la hinchazón fue proporcional a la cantidad de glucosa contenida en la solución amortiguadora de glucosa (BFS).

El uso de hidrogeles no está limitado a la capa; el hidrogel también es usado como núcleos que luego son removidos. Gokmenn et al. demostró esto al usar dispositivos microfluídicos para crear núcleos de hidrogel y luego empleó LBL para obtener una microcápsula vacía de varios micrómetros. En ese estudio los núcleos fueron cubiertos por seis capas alternas de nano partículas de platino (Ptnp) y diazoresina (DAR) (Gokmen, Geest, Hennink, \& Prez, 2009). Dado a que Dex-Hema fue empleado para fabricar los núcleos, hidróxido de sodio fue empleado para removerlo ya que Dex-Hema es degradable en $\mathrm{NaOH}$. La microcápsula resultante está en el orden de los cientos de micras.

Los estudios mencionados requieren un núcleo que debe ser removido, sin embargo en el trabajo de Wan et al. (Wan \& Stone, 2012), burbujas independientes fueron cubiertas con una cubierta polimérica usando un dispositivo microfluídico. El método consiste en la fabricación de microgotas que poseen un único núcleo de gas y las mismas están dispersas en una fase de aceite. La fase de aceite contiene precursores que permiten una reacción sol-gel entre la fase acuosa que rodea las burbujas y la fase continua. El resultado es una cápsula vacía (núcleo de gas) con una cubierta dura. Uno de los parámetros claves para estabilizar las burbujas dentro de las gotas es la viscosidad de la fase acuosa. En ese estudio, la viscosidad fue incrementada añadiendo glicerol. Dado a que los precursores son silano y butóxido de titanio, las cápsulas resultantes estaban hechas de silica o de titanio. La figura 10 muestra un dispositivo microfluídico y las cápsulas vacías resultantes. 


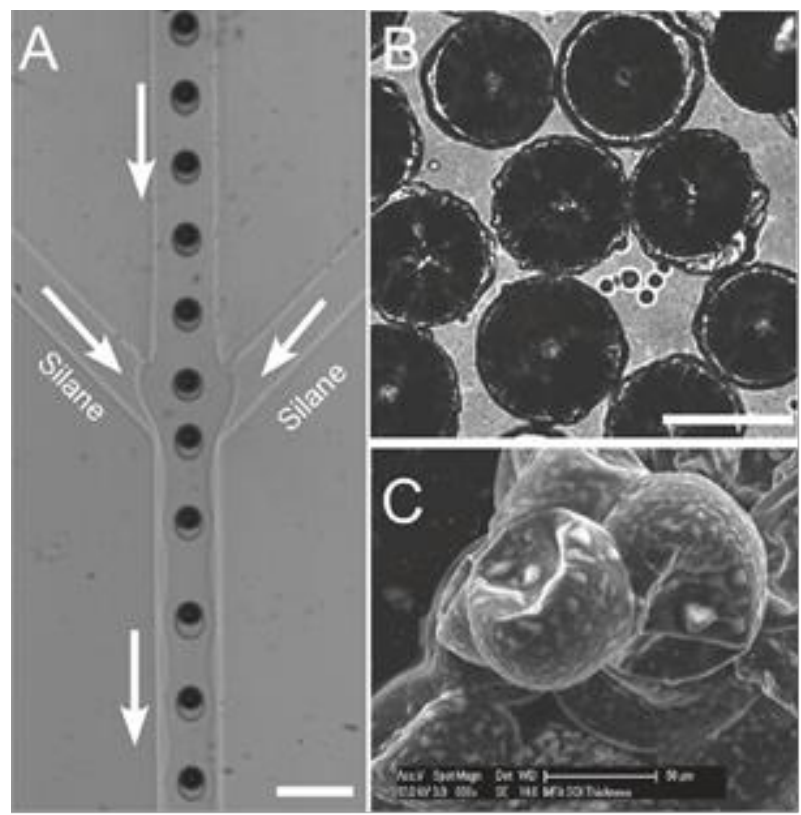

Figura 10: Cápsulas de dispositivos microfluídicos. La cápsula final tenía un tamaño de $60 \mu \mathrm{m}$, sin embargo nano partículas también fueron obtenidas de este proceso.

(Wan \& Stone, 2012)

\section{Método de evaporación de solvente}

El método de evaporación de solvente es un método común. La evaporación del solvente es un aspecto clave en el proceso de formación de microcápsulas vacías dado a que la formación de la capa depende de sobresaturar la concentración del polímero alrededor del núcleo y luego el mismo se remueve para finalmente obtener una cápsula vacía. Sin embargo, con ésta técnica, obtener una microcápsula vacía de un solo núcleo es un reto. Makuta et al. (Makuta, takada, Daiguji, \& Talemura, 2009) introdujeron un nuevo proceso para funcionalizar microburbujas con una cubierta polimérica delgada y que estuviera en un rango micrométrico para aplicaciones de ultrasonido. Este método fue llamado el "método de la plantilla de burbuja." En este método microcápsulas vacías de ácido poliláctico (PLA) fueron fabricadas usando microburbujas que nuclean dentro de gotas de una solución de PLA en diclorometano. Las gotas de PLA y diclorometano son sumergidas en una fase continua acuosa de ya sea ácido de polivinil (PVA) o agua (Cornejo, daiguji, \& Takemura, Factors Affecting the Size and Uniformity of Hollow Poly(lactic acid) Microcapsules Fabricated from Microbubble Templates). Las microburbujas cubiertas con PLA se forman cuando PLA se adsorbe a la superficie de la microburbujas y entonces, espontáneamente, son liberadas del interior de las gotas de la solución de PLA en diclorometano. El proceso puede ser escalado para la producción masiva de microburbujas para propósitos de aplicaciones de contraste para ultrasonidos. Si bien es cierto que 
las cápsulas obtenidas son de menor tamaño que las producidas con otros métodos, la uniformidad de las mismas no fue comprometida y el tamaño final de las cápsulas es el requerido para diagnósticos de ultrasonido (Cornejo, Sakurai, Daiguji, \& Takemura, 2013). Microscopía fluorescente reveló que las cápsulas tienen un mononúcleo de aire. Adicional a esto, Sakurai et al. (Sakurai, Cornejo, Daiguji, \& Takemura, 2013) desarrolló una variante del procedimiento, el método de Gas/O/W, en el mismo se incrementó el tamaño de la cápsula para poder emplear esas cápsulas a aplicaciones ingenieriles.

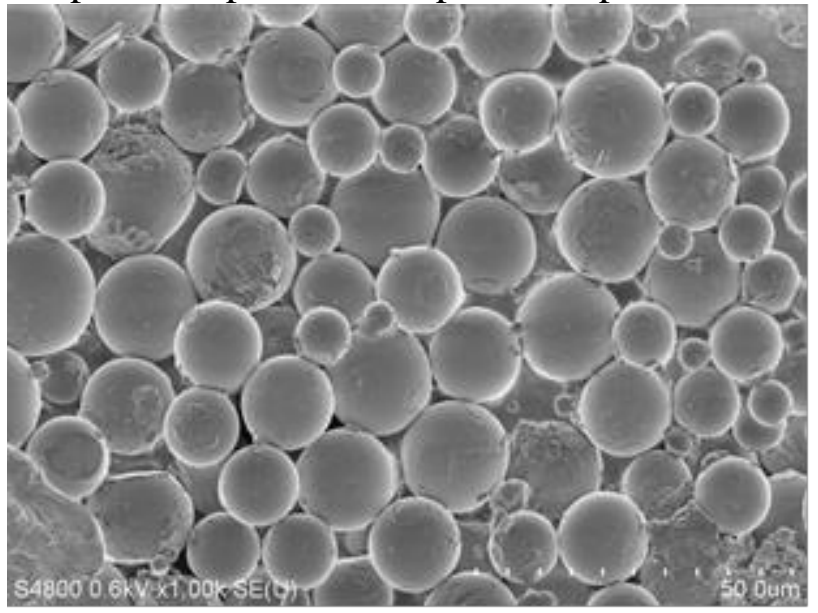

Figura 12: Microcápsulas vacías fabricadas usando el método Gas/O/W.

Las micro cápsulas creadas en Gas/O/W son más grandes que aquellas fabricadas en el método de la plantilla de burbuja. No solo se apreciaron cápsulas con un mononúcleo sino además cápsulas con varios núcleos.

\section{Conclusión}

Este documento abarca las necesidades de fabricar micro cápsulas vacías para usos farmacéuticos y sus correspondientes retos, así como también los métodos de fabricación que son escalables y dan lugar a microcápsulas de tamaño uniforme con mononúcleo. Todos los métodos descritos son maneras fáciles de sintetizar micro cápsulas vacías de tamaño controlables. De todas las técnicas, microfluídicos permite controlar con mayor precisión el tamaño del producto final y por ende las propiedades mecánicas de las mismas pueden ser controladas. Sin embargo, EHDA y CAN-BD tienen la capacidad de producir en gran escala y con la mayor rentabilidad en el proceso de producción. En el caso del método de evaporación de solvente, su mérito consiste en la simplicidad del método puesto que no se necesita ningún tipo de fuerza o mecanismo externo para nuclear la burbuja, lo que permite analizar el fenómeno de nucleación y estabilización de burbuja en una solución líquida sobresaturada de gas con mayor facilidad. 


\section{References:}

1. Dahan, A., \& Hoffman, A. (2008). Rationalizing the selection of oral lipid based drug delivery systems by an invitro dynamic lipolysis model for improved oral bioavailabilitry of poorly water soluble drugs. Journal of Controlled Release, 129, 1-10.

2. Allen, T. M., \& Cullis, P. R. (2004). Drug delivery systems: Entering the Mainstream. Science, 303, 1818-1822.

3. Bagaria, H., Kadali, S., \& Wong, M. (2011). Shell thickness control of nanoparticle-polymer assembled microcapsules. Chemistry of Materials, 23, 301-308.

4. Baker, M. (2010). Homing in on Delivery. Nature, 464, 1225-1228.

5. Barrat, G. (2002). Colloidal drug carriers: achievements and perspectives. Cellular and Molecular Life Sciences, 60, 21-37.

6. Bejerknes, K., Sontum, P., Smistad, G., \& Agerkvist, I. (1997). Preparation of polymeric Microbubbles: formulation studies and product characterization. International Journal of Pharmaceutics , 158, 129-136.

7. Benita, S. (2006). Microencapsulation: Methods and Industrial Applications (2nd ed.). Boca Raton, FL: CRC Press.

8. Bertling, J., Blömer, J., \& Kümmel, R. (2004). Hollow Microspheres. Chemical Engineering Technology, 27, 829-837.

9. Bertrand, P., Jonas, A., Lashewsky, A., \& Legras, R. (2000). Ultrathin polymer coatings by complexation of polyelectrolytes at interfacessuitable materials, structure and properties. Macromolecular Rapid Communiucations, 21, 319-348.

10. Bommarius, A. S., \& Karau, A. (2005). Deactivation of Formate Dehydrogenase (FDH) in Solution and at Gas-Liquid Interfaces. Biotechnology Progress, 21, 1663-1672.

11. Borden, M., \& Longo, M. (2002). Dissolution Behavious of Lipid Monolayer-Coated, Air filled Microbubbles: Effect of Lipid Hydrophobic Chain Lenght. Langmuir, 18, 9225-9233.

12. Cao, L. (2005). Carrier-bound Immobilized enzymes: Principles applications nd design (2nd ed.). wiley-VCH Verlag $\mathrm{GmBH}$.

13. Cape, S., Villa, J., Huang, E., Yang, T.-H., Carpenter, J., \& Sievers, R. (2008). Preparation of Active Proteins. vaccines and Pharmaceuticals as fine Powders using Supercritixcal or Near Critical fluids. Pharmaceutical Research, 25, 1967-1990.

14. Caruso, F. (2000). Hollow Capsule Processing through Colloidal Templating and Self-Assembling . Chemistry: An European Journal, 6, 413-418.

15. Caruso, F., Lichtenfield, H., Giersig, M., \& Mohwald, H. (1998). Electrostatic Self-Assembly of Silica Nanoparticle-Polyelectrolyte 
Multilayers on Polyestyrene Latex Particles. Journal of the American Chemical Society, 120, 8523-8524.

16. Caussette, M., Gaunand, A., Planche, H., Colombié, S., Monsan, P., \& Lindet, B. (1999). Lysozyme inactivation by inert gas bubbling: Kinetics in a bubble column reactor. Enzyme and Microbial Technology, 24, 412-418.

17. Chaize, B., \& Fournier, D. (2004). Sorting out molecules reacting with acetylcholinesterase by enzyme encapsulation in liposome. Biosensors and Bioelectronics, 20, 628-632.

18. Chang, M.-W., Edirisinghea, M., \& Stride, E. (2013). Ultrasound mediated release from stimuli-responsive core-shell capsules. Journal of Material Chemistry B, 1, 3962-3971.

19. Chang, M.-W., Stride, E., \& Edirisinghe, M. (2010). Controlling the thickness of hollow polymeric microspheres prepared by electrohydrodynamic atomization. Journal of the Royal Society Interface , 7, 451-460.

20. Cheng, S. Y., Yuen, M. C., Kan, C. W., Cheuk, K. K., Chui, C. H., \& Lam, K. H. (2009). Cosmetic textiles with biological benefits: Gelatin microcapsules containing Vitamin C. International Journal of Molecular Medicine, 24, 411-419.

21. Choi, C.-H., Jung, J.-H., Kim, D.-W., Chungc, Y.-M., \& Lee, C.-S. (2008). Novel one-pot route to monodisperse thermosensitive hollow microcapsules in a microfluidic system. Royal Society of Chemistry, 8, 1544-1551.

22. Choi, W. S., Park, J.-H., Koo, H. Y., Kim, J.-Y., Cho, B., \& Kim, D.Y. (2005). "Grafting-From" Polymerization inside a Polyelectrolyte Hollow-Capsule Microreactor. Angewandte Chemie International Edition, 44, 1096-1101.

23. Colombié, S., Gaunand, A., \& Lindet, B. (2001). Lysozyme inactivation and aggregation in stirred-reactor. Journal of Molecular Catalysis B: Enzymatic, 11, 559-565.

24. Colvin, V. (2003). The Potential Environmental Impact of Engineered Nanomaterials. Nature Biotechnology, 21, 1166-1170.

25. Cornejo, J. J., daiguji, H., \& Takemura, F. (s.f.). Factors Affecting the Size and Uniformity of Hollow Poly(lactic acid) Microcapsules Fabricated from Microbubble Templates.

26. Cornejo, J. J., Sakurai, D., Daiguji, H., \& Takemura, F. (2013). Kinetics of Formation of Hollow Poly(lactic acid) Microcapsules Fabricated from Microbubbles Templates. Soft Matter, Submitted.

27. Crotts, G., \& Park, T. (1995). Preparation of porous and nonporous biodegradable polymeric hollow microspheres. Journal of Controlled Release, 35, 91-105. 
28. Daiguji, H., Makuta, T., Kinoshita, H., Oyabu, T., \& Takemura, F. (2007). Fabrication of Hollow melamine-formaldehyde microcapsules from microbubble templates. Journal of Physical Chemistry B , 111, 8879-8884.

29. Daiguji, H., Matsuoka, E., \& Muto, S. (2010). Fabrication of hollow poly-allylamine hydrochloride/poly-sodium styrene sulfonate microcapsules from microbubble templates. Soft Matter, 6, 1892-1897.

30. Daiguji, H., Takada, S., Molino, J. J., \& Takemura, F. (2009). Fabrication of Hollow Poly(lactic acid) Microcapsules from Microbubble Templates. Journal of Physical Chemistry B, 113, 15002150009.

31. de Jong, N., Ten Cate, F., Lancee, C., Roelandt, J., \& Bom, N. (1991). Principles and recent developments in ultrasound contrast agents. Ultrasonics, 4, 324-330.

32. Decher, G. (1996). Comprehensive Supramolecular chemistry (1st ed., Vol. 9). Pergamon Press, Oxford.

33. Dubas, S. T., \& Schlenoff, J. B. (1999). Factors Controlling the Growth of Polyelectrolyte Multilayers. Macromolecules, 32, 81538160.

34. Dubey, R., Shami, T., \& KU, R. B. (2009). Microencapsulation Tehcnology and Applications. Defence Science Journal, 59, 82-95.

35. F. Caruso, R. C. (1998). Nanoengineering of Inorganic and Hybrid Hollow Spheres by colloidal Templating. Science , 282, 1111-1114.

36. Fang, Y.-Y., Lee, W.-R., Shen, S.-C., \& Huang., Y.-L. (2006). Effect of liposome encapsulation of tea catechins on their accumulatoin in basal cell carcinomas. Journal Dermatological Science, 42, 101-109.

37. Feng, Z., Wang, Z., Gao, C., \& Shen, J. (2007). Hollow microcapsules with a complex polyelectrolyte shell structure fabricated by polymerization of 4-vinylpyridine in the presence of poly(sodium 4styrenesulfonate) and silica particles. Materials Letters, 61, 25602564.

38. Geest, B., Déjugnat, C., Sukhorukov, G., Braeckmans, K., DeSmedt, S., \& Demeester, J. (2005). Self Rupturing Microcapsules. Advanced Materials, 17, 2357-2361.

39. Ghosh, S. L. (2006). Functional Coatings by Polymer Encapsulation (1st ed.). WILEY-VCH Verlag GmbH \& Co. KGaA.

40. Gokmen, M. T., Geest, B. G., Hennink, W. E., \& Prez, F. E. (2009). "Giant" Hollow Multilayer Capsules by Microfluidic Templating. Applied Materials \& interfaces, 1, 1196-1202.

41. Hwang, Y., Jeong, U., \& Cho, E. (2008). Production of uniform-sized polymer core-shell microcapsules by coaxial electrospraying. Langmuir, 18, 2446-2451. 
42. Ikeda, S., Ishino, S., Harada, T., Okamoto, N., Sakata, T., Mori, H., . . . Matsumura, M. (2006). Ligand-Free Platinum Nanoparticles Encapsulated in a Hollow Porous Carbon Shell as a Highly Active Heterogeneous Hydrogenation Catalyst. Angewandte Chemie, 45, 7063-7066.

43. Ikeuchi, M., Tane, R., \& Ikuta, K. (2012). Electrospray Deposition and Direct Patterning of Polylactic Acid Nanofibrous Microcapsules for Tissue Engineering. Biomedical Microdevices, 14, 35-43.

44. Imhof, A. (2001). Preparation and Characterization of Titania-Coated Polysterene Spheres and Hollow Titania Shells. Langmuir, 17, 35792585.

45. Kawahashi, N., \& Matijevic, E. (1991). Preparation of Hollow Spherical PArticles of Yttrium Compounds. Journal of Collooid and INterface Science, 143(103-110).

46. Kim, J.-W., Fernandez-Nieves, A., Nily Dan, A. U., MArquez, M., \& Weitz, D. (2007). Colloidal assembly route for responsive colloidosomes with tunable permeability. Nano Letters, 7, 2876-2880.

47. Kim, J.-W., Utada, A., Fernández-Nieves, A., Hu, Z., \& Weitz, D. (2007). Fabrication of Monodisperse Gel Shells and Functional Microgels in Microfluidic Devices. Angewandte Chemie International Edition, 1819-1822, 46.

48. Kim, W., \& Kim, S. (2010). Multishell Encapsulation Using a Triple Coaxial Electrospray System. Analytical Chemistry, 82, 4644-4647.

49. Knoll, W. (1996). Self-Assembled microstructures at interfaces. Current Opinions in Colloid \& Interface Science, 1, 137-143.

50. Korneev, D., Lvov, Y., G.Decher, Schmitt, J., \& Yaradaikin, S. (1995). Neutron reflectivity of self assembled film superlattices with alternate layers of deuterated and hydrogenated polyesterenesulfonate and polyallylamine. Physica B, 1995, 954-956.

51. Kumar, S., Nakka, S., Rajabalaya, R., Kumar, H., Halder, T., Palanisamy, M., . . Nanda, A. (2011). Microencapsulation Techniques and its Practices. International Journal of Pharmaceutical Science Technology, 6, 1-23.

52. Lachman, L., Lieberman, H., \& Kanig, J. (2010). The Theory and Practice of Industrial Pharmacy (3rd ed.). Lea and Febiger.

53. Lakshmi, S., Figoli, A., Buonomenna, M., Colemme, G., \& Drioli, E. (2012). Preparation and Characterization of Porous and Nonporous Polymeric Microspheres by the Phase Inversion Process. Advances in Polymer Technology, 00, 1-11.

54. Lakshmi, S., Fioli, A., Buonomenna, M., Golemme, G., \& Drioli, E. (2012). Preparation and Characterization of Porous and Nonporous 
Polymeric Microspheres by the Phase Invertion Process. Advances in Polumer Technology, 00, 1-11.

55. Lathia, J. D., Leodore, L., \& Wheatley, M. (2004). Polymeric contrast agent with targeting potential. Ultrasonics, 42, 763-768.

56. Lawrence, D., Cai, T., Hu, Z., Marquez, M., \& Dinsmore, A. (2007). Temperature-Responsive Semipermeable Capsules Composed of Colloidal Microgel Spheres. Langmuir, 23, 395-398.

57. Lee, K., Jung, Y., \& Oh, S. (2003). Synthesis of Tin-Encapsulated Spherical Hollow Carbon for Anode Material in Lithium Secondary Batteries. Journal of American Chemical Society, 125, 5652-5653.

58. Lin, P.-L., Eckersley, R. J., \& Hall, E. A. (2009). Ultrabubble: A Laminated Ultrasound Contrast Agent with Narrow Size Range. Advanced Materials, 21, 3949-3952.

59. Liu, J., \& Wilcox, D. (1995). Factors influencing the formation of hollow ceramic microspheres by water extraction of colloidal droplets. Journal of Material Research, 10, 84-94.

60. Luo Yan, C. S. (2002). Preparation and properties of disperse dye microcapsules. Coloration Technology, 119, 37-40.

61. Makuta, T., takada, S., Daiguji, H., \& Talemura, F. (2009). Simple fabrication of hollow poly-lactic acid microspheres using uniform microbubbles as templates. Materials Letters, 63, 703-705.

62. McKelvey, C. A., Kaler, E. W., Zasadzinski, J. A., Coldren, B., \& Jung, H.-T. (2000). Templating Hollow Polymeric Spheres from Cationic Equilibrium Vesicles: Synthesis and Characterization. Langmuir, 16, 8285-8290.

63. Meng, F., Zhong, Z., \& Feijen, J. (2009). Stimuli-Responsive Polymersomes for Programmed Drug Delivery. Biomacromolecules, 10, 197-209.

64. Molino, J., Matsuoka, E., \& Daiguji, H. (2011). Size control of hollow poly-allylamine hydrochloride/poly-sodium styrene sulfonate microcapsules using the bubble template method. Soft Matter, 7, 18971902.

65. Murphy, E., \& Wudl, F. (2010). The World of Smart Healable Materials. Progress in Polymer Science, 35, 223-251.

66. Narayan, P., \& Wheatley, M. (1999). Preparation and characterization of hollow microcapsules for use as ultrasound contrast agents. Polymer Engineering and Science, 39(11), 2242-2255.

67. Narayan, P., \& Wheatley, M. (1999). Preparation and characterization of hollow micrpcapsles for use as ultrasound contrast agents. Polymer Engineering and Science, 39, 2242-2255.

68. NEU, B., VOIGT, A., HNER, R. M., LEPORATTI, S., GAO, C. Y., DONATH, E., ... UMLER, H. B. (2001). Biological cells as templates 
for hollow microcapsules. Journal of Microencapsulation , 18, 385395.

69. Nie, Z., Xu, S., Seo, M., Lewis, p., \& Kumacheva, E. (2005). Polymer Particles with Various Shapes and Morphologies Produced in Continuous Microfluidic Reactors. Journal of American chemical Society, 127, 8058-8063.

70. Ouyang, W., Chen, H., Jones, M. L., Metz, T., Haque, T., Martoni, C., \& Prakash, S. (2004). Artificial Cell Microcapsule for Oral Delivery of Live Bacterial Cells for Therapy: Design, Preparation, and In-Vitro Characterization. Journal of Pharmaceutical Science, 7, 315-324.

71. Pardeike, J., Hommoss, A., \& Muller, R. (2009). Lipid nanoparticles (SLN,NLC) in cosmetic and pharmaceutical dermal products. INternational Journal of Pharmaceutics, 366, 170-184.

72. Parhi, R., \& Suresh, P. (s.f.). Supercritical Fluid Technology: A Review. Advanced Pharmaceuticval Science and Tehcnology, 1, 1336.

73. Park, J., Choi, Y.-W., Kim, K., Chung, H., \& Sohn, D. (2008). Aggregation Processes of a Weak Polyelectrolyte, Poly(allylamine) Hydrochloride. Bulletin of the Korean Chemical Society, 29, 104-110.

74. Park, J.-H., Oh, C., Shin, S.-I., Moon, S.-K., \& Oh, S.-G. (2003). Preparation of hollow solica microspheres in W/O emulsions with polymers. JOurnal of Colloid and Interface Science , 266, 107-114.

75. Peyratout, C., \& Dahne, L. (2004). Tailor-Made Polyelectrolyte Microcapsules From Multilayers to Smart Containers. Angewandte Chemie International Edition, 43, 3762-3783.

76. Pisani, E., Tsapis, N., Paris, J., Nicolas, V., Cattel, L., \& Fattal, E. (2006). Polymeric Nani/Microcapsules of Liquid Perfluorocarbons for Ultrasonic Imaging: Physical Characterization. Langmuir, 22, 43974402.

77. Plesset, M., \& Sadhal, S. (1982). On the stability of gas bubbles in liquid gas solutions. Applied Science Research, 38, 133-141.

78. Preparation of hollow polylactide microcapsules through premix membrane emulsification-Effects of nonsolvent Properties. (2008). Journal of Membrane Science, 325, 665-671.

79. Rave, P., \& Johnson, G. (2001). Biology (6th ed.). McGraw Hill.

80. Saihi, D., Vroman, I., Giraud, S., \& Bourbigot, S. (2006). Microencapsulation of ammonium phosphate with a polyurethane shell. PartII. Interfacial polymerization tehcnique. Reactyive and Functional Polymers, 66, 1118-1125.

81. Sakurai, D., Cornejo, J. J., Daiguji, H., \& Takemura, F. (2013). Hollow Poly(lactic acid) Microcapsules Fabricated in Gas/O/W Method and 
Bubble Template Method. Journal of Material Chemistry A, DOI: 10.1039/C3TA12587D .

82. Sang, X. M., Yang, X. J., Cui, Z. D., Zhu, S. L., \& Sheng, J. J. (2005). Nano-SiO2 Doped Polystyrene Materials for Inertial Confinement Fusion Targets. Macromolecular Science B, 44, 237-248.

83. Sboros, V. (2008). Response of Contrast Agents to Ulrrasound. Advanced Drug Delivery, 60, 1117-1136.

84. Schutt, E. G., Klein, D. H., Mattrey, R. M., \& Riess, J. (2003). Inyectable Microbubbles as Contrast Agents for Diagnostic Ultrasound Imaging: The Key Role of Perfluorochemicals . Angewandte Chemie International Edition, 42, 3218-3235.

85. Schutt, E., Klein, D., Mattrey, R., \& Riess, J. (2003). Injectable Microbubbles as Contrast Agents for Diagnostic Ultrasound Imaging: The Key Role of Perfluorochemicals. Angewandte Chemistry International, 3218-3235.

86. Selvam, S., Thomas, S. P., Hamm-Alvarez, S., Schechter, J. E., Stevenson, D., \& Mircheff, A. K. (2006). Current Status of Gene Delivery and Gene Therapy in lacrimal gland using viral vectors. Advanced Drug Delivery Reviews, 58, 1243-1257.

87. Seo, M., Nie, Z., Xu, s., Mok, M., Lewis, P., Graham, R., \& Kumacheva, E. (2005). Continous Microfluidic Reactors for polymer Particles. Langmuir, 21, 11614-11622.

88. Shalaby, S. (1994). Biomedical Polymers (1st ed.). Hanser Publishers.

89. Shchukin, D. G., Köhler, K., Möhwald, H., \& Sukhorukov, G. B. (2005). Gas-Filled Polyelectrolyte Capsules. Angewandte Chemie International Edition, 44, 3310-3314.

90. Shchukin, D., \& Sukhorukov, G. (2004). Nanoparticle Synthesis in Engnieered Organic Nanoscale Reactors. Advanced Materials, 16, 671.

91. Shingo Okushima, T. N., torii, T., \& Higushi, T. (2004). Controlled Production of Monodisperse Double Emulsions by Two-Step Droplet Breakup in Microfluidic Devices. Langmuir, 20, 9905-9908.

92. Shun Li, S. K., Feld, K., \& Grim, w. (1988). Recent Advances in Microencapsulation Technology and equipment. Drug Development and Industrial Pharmacy, 14, 353-376.

93. Si, T., Zhang, L., Li, G., Roberts2, C. J., Jia, L., Yin, X., \& Xu, R. (2012). Coaxial electrospray for multinodal imaging and image-guided therapy. Proceedings of SPIE, 8216, 1-10.

94. Siepman, J., \& A, G. (2001). Mathematical modeling of bioerodible, polymeric drug delivery systems. Advanced Drug Delivery Review, 48, 229-247. 
95. Sievers, R., Quinn, B., Cape, S., Searles, J., Braun, C., Bhagwat, P., . . - Chen, D. (2007). Near-Critical fluid micronization of stabilized vaccines; antibiotics and anti-virals. Journal of Supercritical Fluids, 42, 385-391.

96. Sohn, K., Na, Y., Chang, H., Roh, K.-M., Jang, H., \& Huang, J. (2012). Oil absorbing graphene capsules by capillary molding. Chemical Communications, 48, 5968-5970.

97. Sukhorukov, G., Fery, A., \& Mohwald, H. (2005). Intelligent microand nanocapsules. Progress in Polymer Science, 30, 885-897.

98. Tamae, H., Sumi, T., \& Yasuda, H. (1996). Preparation and Characteristics of Fine Hollow Carbon Particles. Journal of Colloid and Interface Science, 177, 325-328.

99. Thiering, R., Dehghani, F., \& Foster, N. (2001). Current issues relating to anti-solvent micronisation techniques and their extension to industrial scales. The Journal of Supercritical Fluids, 21, 159-177.

100. Thorsen, T., Roberts, R., Arnold, F., \& Quake, S. (2001). Dynamic Patter Formation in a Vesicle-Generating Microfluidic Devie. Physical Review Letters, 86, 4163-4166.

101. Tsukuk, V., \& Singamaneni, S. (2012). Scanning Probe Microscopy of Soft Matter: Fundamentals and Practices (1st ed.). Wiley-VCH Verlag GmbH \& Co.

102. Vonnegut, B., \& Neaubauer, R. (1952). Production of monodisperse liquid particles by electrical atomization. Journal of Colloid Science, 6, 616-622.

103. Wan, J., \& Stone, H. (2012). Coated Gas Bubbles for the Continuous Synthesis of Hollow Inorganic Particles. Langmuir, 28, $37-41$

104. Wang, B., Zhao, Q., Wang, F., \& Gao, C. (2006). Biologically Driven Assembly of Polyelectrolyte Microcapsule Patterns To Fabricate Microreactor Arrays $\dagger$. Angewandte Chemie International Edition, 45, 1560-1563.

105. Waterbeend, H. v., Dennis Smith, K. B., \& Walker, D. (2001). Property-Based Design: Optimization of Drug Absorption and Pharmacokinetics. Journal of Medicial Chemistry, 1313-1332.

106. Wei, J., Ju, X.-J., Xie, R., Mou, C.-L., Lin, X., \& Chu, L.-Y. (2011). Novel cationic pH-responsive poly(N,N-dimethylaminoethyl methacrylate) microcapsules prepared by a microfluidic technique. Journal of Colloid and Interface Science, 357, 101-108.

107. Wise, D., L, B.-P., Klibanow AM, M. A., Peppas, N., Trantolo, D., \& Wnek GE, Y. M. (2000). Handbook of pharmaceutical Controlled Release Technology. Marcel Dekker. 
108. Wu, C., Yu, C., \& Chu, M. (2011). A gold nanoshell with a silica inner shell synthesized using liposome templates for dexorubicin loading and near-infrared photothermal therapy. International journal of Nanomedicine, 6, 807-813.

109. Xu, X., \& Asher, S. A. (2004). Synthesis and Utilization of Monodisperse Hollow Polymeric Partciels in Photonic Crystals. Journal of the American Chemical Society, 126, 7940-7945.

110. Yang, H., Qiao, X., Hong, W., \& Dong, L. (2013). Core-Shell Microcapsules with Embedded Microactuators for Regulated Release. Microelectromechanical Systems, 22(509-518).

111. Yin, Y., Lu, Y., Gates, B., \& Xia, Y. (2001). Synthesis and Characterization of Mesoscopic Hollow Spheres of Ceramic Materials with Functionalized Interior Surfaces. Chemistry of Materials, 13, 1146-1148.

112. Zeleny, J. (1915). On the conditions of instability of electrified drops with applications to the electrical discharge from liquid points. Procedings of Cambridge Philosofica Society, 18, 71-83.

113. Zhang, H., Li, D., Shao, G., \& Yuan, Z. (2009). A simple method to prepare titania nanomaterials of core-shell structure, hollow nanospheres and mesoporous nanoparticles. Science in China Series B: Chemistry/Springer, 52, 1498-1503.

114. Zhang, M.-J., Wei Wang, Xie, R., Ju, X.-J., Liu, L., Gu, Y.-Y., \& Chu, L.-Y. (2013). Microfluidic fabrication of monodisperse microcapsules for glucose-response at physiological temperature. Soft Matter, 9, 4159-4159.

115. Zhang, Q., Wang, L., Wei, Z., Wang, X., Long, S., \& Yang, J. (2012). A new simple method to prepare hollow PES microspheres. Colloid Polymer Science, 290, 1257-1263.

116. Zhao, Q., Han, B., Wang, Z., Gao, C., Peng, C., \& Shen, J. (2007). Hollow chitosan-alginate multilayer microcapsules as drug delivery vehicle: doxorubicin loading and in vitro and in vivo studies. Nanomedicine: Nanotechnology, Biology, and Medicine, 3, 63-74.

117. Zhao, Q., Mao, Z., Gao, C., \& Shen, J. (2006). Assembly of multilayer microcapsules on $\mathrm{CaCO} 3$ particles from biocompatible polysaccharides. Journal of Biomaterials Science, Polymer Edition, 17, 997-1014. 